\title{
ТВЁРДЫЕ БЫТОВЫЕ ОТХОДЫ И COVID-19 (ОБЗОР ЛИТЕРАТУРЫ)
}

\author{
П.В. Журавлёв ${ }^{1,2}$, А.С. Калюжин ${ }^{1}$, Н.В.Алексанина ${ }^{1}$, М.А. Кулак ${ }^{1}$, М.Н. Гапон ${ }^{1}$, \\ Т.И. Твердохлебова ${ }^{1,2}$ \\ ${ }^{1}$ ФБУН «Ростовский научно-исследовательский институт микробиологии и \\ паразитологии» Роспотребнадзора, г. Ростов-на-Дону, Российская Федерация \\ ${ }^{2}$ ФГБОУ ВО «Ростовский государственный медицинский университет» Минздрава \\ России, г. Ростов-на-Дону, Российская Федерация
}

\section{SOLID WASTE AND COVID-19 (LITERATURE REVIEW)}

\author{
P.V. Zhuravlev ${ }^{1,2}$, A.S. Kalyuzhin ${ }^{1}$, N.V. Aleksanina ${ }^{1}$, M.A. Kulak ${ }^{1}$, M.N. Gapon ${ }^{1}$, \\ T.I. Tverdokhlebova ${ }^{1,2}$ \\ ${ }^{1}$ FBUN "Rostov Research Institute of Microbiology and Parasitology" Rospotrebnadzor, \\ Rostov-on-Don Russian Federation \\ ${ }^{2}$ FGBOU HE "Rostov State Medical University" of the Ministry of Health of Russia, \\ Rostov-on-Don, Russian Federation
}

Резюме. В обзоре рассмотрены различные аспекты обращения с твёрдыми бытовыми и медицинскими отходами в период пандемии. Показана роль медицинского сектора в общемировом увеличении отходов и их влияния на загрязнение окружающей среды. Отражены современные методы противодействия биологической угрозе загрязнения бытовыми и медицинскими отходами, контаминированными возбудителем COVID-19. Показано, что во время пандемии коронавирусной инфекции резко выросло производство одноразовых изделий. Помимо влияния на экологию при неправильной утилизации предметов, контаминированных SARS-CoV-2, повышается риск распространения коронавирусной инфекции. Многочисленными исследованиями подтверждена трёхдневная жизнеспособность вируса COVID-19 на пластике, что увеличивает риск заражения и является важным для эпидемиологической оценки ситуации. Представлены разработанные в Российской Федерации и других странах мира меры по утилизации твёрдых бытовых и медицинских отходов.

Ключевые слова: COVID-19, твёрдые бытовые и медицинские отходы, экология, загрязнение пластиком, медицинские маски, SARS-CoV-2

Summary. The review examines various aspects of the management of solid household and medical waste during a pandemic. The role of the medical sector in the global increase in waste and their impact on environmental pollution is shown. Modern methods of counteracting the biological threat of pollution with household and medical waste contaminated with the pathogen 
COVID-19 are reflected. It has been shown that during the coronavirus pandemic, the production of disposable products has increased dramatically. In addition to the environmental impact, improper disposal of items contaminated with SARS-CoV-2 increases the risk of the spread of coronavirus infection. Numerous studies have confirmed the three-day viability of the COVID19 virus on plastic, which increases the risk of infection and is important for an epidemiological assessment of the situation. Presented are the measures developed in the Russian Federation and other countries of the world for the disposal of solid household and medical waste.

Keywords: COVID-19, solid household and medical waste, ecology, plastic pollution, medical masks, SARS-CoV-2

Введение. Новая коронавирусная инфекция выявила проблемы, связанные с обращением твёрдых бытовых и медицинских отходов. Потребность в использовании одноразовых пластмассовых изделий и медицинских масок привела к глобальному увеличению их производства. Использование медицинских масок вне лечебных учреждений часто приводит к неправильной их утилизации вместе с обычными бытовыми отходами. При этом происходит загрязнение полигонов и повышается риск заражения коронавирусом сотрудников на сортирующих станциях и других людей, занятых сбором и переработкой бытовых отходов. Рост производства и потребления медицинских отходов во всем мире привёл к экологической проблеме, обусловленной увеличением содержания пластика в окружающей среде. Важным с эпидемиологической точки зрения является распространение инвазивных патогенов, в частности возбудителя COVID-19, на пластиковых частицах. Именно поэтому, большинство европейских стран разрабатывают алгоритмы и методы противодействия экологической и биологической угрозе в условиях пандемии.

Твёрдые бытовые отходы и COVID-19. Пандемия привела к серьезным проблемам при обращении с твёрдыми бытовыми (ТБО) и опасными медицинскими отходами. Максимальным количеством сведений по данному вопросу располагает Китай. Согласно пресс-релизам от 11 марта о совместном механизме государственного совета по профилактике и контролю в Китае [1] количество ТБО в крупных и средних городах сократилось на 30\% во время вспышки заболевания. Тем не менее, в провинции Хубэй образование медицинских отходов резко возросло на 70\%, с высокой долей пластмасс. С 20 января по 31 марта накопленные медицинские отходы во всем Китае составили 207 тыс. тонн. В г. Ухань медицинские отходы увеличились с нормального уровня - 40 т/сут до пикового значения - 240 т/сут, превысив максимальную мощность сжигания - 49 т/сут. Стоимость сжигания опасных медицинских отходов в Китае оценивается в 281,7 - 422,6 \$ США /т по сравнению с 14,1 \$ США/т для ТБО [2].

Системы очистки, разработанные для качества и количества отходов в нормальных условиях, должны справляться с серьёзными изменениями, которые вызывают неординарные ситуации. Технологический анализ необходим для того, чтобы эти системы могли справляться с динамичным и развивающимся характером пандемии.

Кризис, связанный с COVID-19, выявил негативную роль использования пластика в повседневной жизни. С одной стороны, борьба с вирусом требует одноразового 
использования пластика [3], а с другой стороны, одноразовость рассматривается как экологическая ответственность. Следы пластмассовых изделий могут рассматриваться как один из эффективных инструментов экологической оценки загрязнения окружающей среды.

Во время пандемии COVID-19 значительно увеличился спрос на медицинские изделия и одноразовые упаковки. Потребители рассматривают одноразовые пластмассовые изделия как безопасную альтернативу для различного применения. Меры по изменению оборота медицинских отходов, применяемые в разных странах, изменяют как количество, так и качество пластиковых отходов.

Исследования, проведённые Van Doremaul et al. [4] и Kampf et al. [5], показали способность вируса выживать на разных поверхностях, в том числе на пластике. Несмотря на это, одноразовое использование считается важным преимуществом для потребителей, уделяющих приоритетное внимание гигиене. Это привело к увеличению использования и утилизации пластмассовых изделий даже для немедицинских целей. С другой стороны, спрос на пластик в других секторах (например, в автомобильной и авиационной промышленности) снижается в условиях глобального экономического спада.

Система управления отходами. В настоящее время недостаточное внимание уделяется рядом стран туристическим и миграционным потокам, изменяющим количественные показатели отходов.

В Каталонии на фоне снижения миграционной активности производство муниципальных отходов сократилось до 242000 тонн, что на 16,65\% ниже, чем в обычный месяц (282 340 тонн). В Барселоне образование отходов сократилось на 25\% изза отсутствия в городе обычной для неё высокой концентрации сезонной эмиграционной рабочей силы, вносившей вклад в коммерческий сектор, а также из-за отсутствия туристической активности организаций, которые в настоящее время закрыты или сократили свою деятельность [6].

Сбор вторсырья (органика, бумага и картон, стекло, лёгкая упаковка) в Каталонии по сравнению с обычными показателями снизился на 20\% (72 000 и 89000 тонн соответственно). Смешанные отходы снизились в среднем на $12 \%$, а в Барселоне на $17,5 \%$.

Производство медицинских отходов (включая маски, перчатки, комбинезоны) увеличилось на 350\% с середины марта. В мусоросжигательных заводах Каталонии в середине апреля были обработаны 700 из 1200 тонн медицинских отходов [7].

Компании стали создавать запасы, аккумулируя собственные средства, или менять поставщиков, но неопределенность в отношении ответных мер европейских правительств на пандемию усложнила картину прогнозирования спроса на первичное и вторичное сырье.

Ассоциация по твердым отходам Северной Америки, Австралийская ассоциация управления отходами, Ассоциация экологических служб Великобритании, Европейская ассоциация приветствовали признание правительством работников по утилизации отходов в качестве ключевых позиций в жизнеобеспечении городов [8].

Обозначились различия в схемах управления отходами: 
1) в государствах, где системой управления отходами занимается государство и муниципальные компании (Россия, Австралия), не произошло значительных изменений в управлении;

2) где распространены частные компании и операторы вывоза отходов, доля которых составляет до 60-75 \% (как в странах Европы и США), необходимы согласования путей управления отходами с государством, поскольку оно в большей степени определяет роль и вносит вклад в создание промышленного рынка.

Изменились персональные требования для жителей с лёгкой формой COVID-19, которые находятся на самоизоляции. 31 марта Европейский центр профилактики и контроля заболеваний опубликовал документ, содержащий руководство по мерам профилактики и контроля инфекций (МПК) для людей с подозрением или подтверждённым заболеванием COVID-19, определившим новые санитарные рекомендации в обращении с отходами [8].

Индивидуальный мешок для мусора должен быть помещён в комнату пациента, куда он выбрасывает бумажные салфетки и маски для лица. Перчатки и маски для лица, используемые смотрителем и уборщиком, должны быть немедленно помещены во вторую сумку для мусора. Мешки для мусора должны быть закрыты до того, как они будут удалены из комнаты пациента и чаще заменяться; далее они помещаются в несортированный мусор. Никакой специальной деятельности по сбору или другого способа удаления не требуется. Для работников следует соблюдать строгую гигиену рук: использовать моющие средства или дезинфицирующие средства на спиртовой основе [9].

Отрасль муниципальных отходов. Создание протоколов по осуществлению повседневного вывоза отходов находится в ведении национальных властей и проводится на регулярной основе согласно эпидемиологической обстановке.

B связи с COVID-19 повсеместно были изменены рабочие правила в обеспечении специалистов отраслей управления отходами надлежащим защитным оборудованием, а также скорректированы социальные программы и меры поддержки бизнеса: национальные и местные органы власти организовали услуги по уходу за детьми для работников управления отходами, освободили операторов от штрафных санкций за исполнение контрактов с местными властями на время пандемии.

На данный момент отрасль должна сосредоточиться на поддержании работы соответствующих служб. Приоритеты в отрасли управления едины: безопасность для работников в сфере управления отходами; особое внимание своевременной дезинфекции и вывозу опасных отходов; своевременность транспортировки вторичного сырья; разъяснительные программы с просьбой к гражданам быть бережливыми потребителями. Приоритеты меняются в разных регионах в пользу безопасности, если власти считают это целесообразным.

Большинство европейских стран разработали четкий алгоритм и схему действий в условиях пандемии. В нескольких странах проводятся обследования (на национальном, региональном или местном уровнях) для оценки ситуации и предоставления сводных и статистических данных о деятельности по сбору и обработке отходов. В настоящее время доступны данные по Англии, Франции, Испании (Каталония) и Италии (г. Милан) [9]. 
В России работа с медицинскими отходами в период эпидемий любых инфекций, в том числе и новой коронавирусной, регулируется с 2010 года СанПиН 2.1.7.2790.

Все объекты сбора и утилизации работают в обычном режиме. При этом делается акцент на то, что водители мусоровозов, грузчики, сотрудники на сортирующих станциях и другие люди, занятые сбором и переработкой бытовых отходов, находятся в зоне повышенного риска заражения коронавирусом из-за выброшенных масок.

В Российской Федерации существует пять классов опасности отходов. По отечественной классификации считается, что персонал работает с менее опасными. Класс А включает бытовой мусор, твёрдые отходы, эпидемиологически безопасные, которые не требуют особых условий хранения. Класс Б включает отходы медорганизаций, где был контакт с биологическими жидкостями и кровью пациентов, в том числе заражённых инфекционными болезнями; эпидемиологически опасные отходы с биологическими жидкостями пациентов инфекционных отделений.

В России маски вторичной переработке не подлежат, и региональный оператор с ними не работает, поэтому если они оказываются в бытовых, а не в медицинских контейнерах, их перемещают на мусоросжигательный завод (МС3) или полигон.

Любые отходы, образующиеся в немедицинских учреждениях, имеющие вероятность обсеменённости инфекционным агентом COVID-19, должны быть упакованы в двойной мешок, надежно связаны и оставлены на 72 часа до помещения в мусорное ведро, после чего вирус теряет жизнеспособность.

Усиление глобализации и ухудшение эпидемической обстановки, высокая устойчивость SARS-CoV-2 (на срок до 9 дней на инертных поверхностях), а также его способность передаваться от человека к человеку являются ключевыми аспектами для его быстрого распространения [10,11, 12]

Van Doremaul et al. [13] считают, что жизнеспособный вирус COVID-19 может быть обнаружен в различных условиях: до 3 часов после аэрозолизации; до 4 часов на меди; до 24 часов на картоне; до 2-3 дней на пластике и нержавеющей стали. Эта относительно длительная жизнеспособность на исследуемых материалах предполагает потенциальное присутствие вируса на отходах.

Известно, что коронавирус может быть легко инактивирован биоцидными агентами или термической обработкой. Важно подчеркнуть, что гигиенические процедуры рассматриваются как ключ к контролю распространения вируса. Согласно данным Всемирной организации здравоохранения (ВО3), там, где дезактивация не может быть проведена в лабораторной зоне или на месте, загрязнённые отходы должны быть упакованы утверждённым способом для передачи в другое дезактивирующее предприятие. Эту же процедуру следует рекомендовать для отходов пациентов, находящихся на лечении по поводу COVID-19 в домашних условиях. Ненадлежащее обращение с твёрдыми отходами усиливает риск инфицирования сборщиков мусора [14].

Загрязнение окружающей среды медицинскими масками. Ещё одним потенциальным загрязнителем в период пандемии являются медицинские маски. Одноразовые лицевые маски были созданы для защиты работников здравоохранения (HCWs). Во время вспышки атипичной пневмонии в ноябре 2002 года и гриппа H1N1 в 
2009 году было принято решение властей об их использовании населением, чтобы остановить распространение вирусов $[15,16]$.

В настоящее время - в период пандемии, исследователи выступают за использование масок для лица населением, пока полностью не будет изучен способ передачи COVID-19 [17]. Утверждается, что это будет способствовать уменьшению количества касаний человеком лица немытыми руками и снижению вероятности заражения, а также исключению аэрозольного механизма передачи инфекции при чихании и кашле. Эффективность использования лицевых масок для защиты от респираторной инфекции была подтверждена во время хаджа мусульман $[16,18,19]$.

Согласно оценкам ВОЗ, приблизительно 89 миллионов медицинских масок ежемесячно были использованы для профилактики заражения COVID-19 [20]. Высокий спрос привел к беспрецедентному росту мирового производства масок для лица, которые изготавливаются с использованием полимерных материалов. Китай увеличил ежедневное производство медицинских масок до 14,8 млн. к февралю 2020 года [21]. По данным Министерства экономики, торговли и промышленности Японии [22], по состоянию на апрель 2020 года в стране производилось ежемесячно более 600 млн. масок. Ожидалось, что спрос на маски значительно увеличится, поскольку число людей, инфицированных вирусом COVID-19, в мире резко нарастало [23].

Увеличение производства и потребления масок для лица во всем мире породило новую экологическую проблему, добавив их к огромным отходам пластмассы и пластика в окружающей среде. Попадая в систему сброса сточных вод, они достигают пресной и морской воды, добавляясь к общей массе отходов пластмасс в водной среде. Так, OceansAsia - организация, занимающаяся защитой и исследованиями загрязнения морской среды, сообщила в феврале 2020 года о наличии в Гонконге лицевых масок в океане [24].

Попадая в окружающую среду (на свалках, в пресной воде, океанах, мусор в общественных местах) и разлагаясь до размера 5 мм частиц, известных как микропластики, одноразовые лицевые маски могут стать новым источником микропластических волокон. Экологические последствия загрязнения пластмассами и пластиковыми частицами были перечислены и представлены учеными в научной литературе [25-29]. Они представляют угрозу для водных организмов, которые составляют основную часть пищевой цепи для людей. Попадание в пищу человека пластиковых частиц, вызывает обеспокоенность по поводу глобальной безопасности пищевых продуктов [24].

Имеется информация, что присутствие пластмасс в окружающей среде вносит значительный вклад в изменение климата из-за выбросов углерода и увеличивает риски для глобальной пищевой цепи[30, 31]. Неправильная утилизация масок для лица может стать причиной вспышки заболеваемости, поскольку пластиковые частицы распространяют инвазивные патогены [30].

Несмотря на то, что в настоящее время не существует единого международного регламента по регулированию пластмасс и управлению загрязнением, некоторые страны приняли жёсткие меры по пресечению тотального распространения пластиковых отходов. Проект по морским отходам Национального управления океанических и атмосферных исследований (NOAA), утверждённый Европейской комиссией в соответствии с законами 
о действиях по морским отходам, возможно, будет способствовать повышению осведомлённости о загрязнении пластиковыми частицами в рамках государственной образовательной программы. В Ирландии, в Китае и Южной Африке с потребителей и розничных продавцов одноразовой продукции взимается налог.

Заключение. На основании научных данных, приведённых в обзоре, можно утверждать, что загрязнение окружающей среды твёрдыми бытовыми отходами на протяжении длительного времени является важной проблемой экологии во всём мире. Применение одноразовых пластмассовых изделий или изделий, содержащих полимерные материалы, широко распространено во всех сферах жизни, особенно в медицине. Во время пандемии новой коронавирусной инфекции резко выросло производство медицинских масок и других одноразовых медицинских изделий, что повышает риск распространения заболевания при неправильной утилизации предметов, контаминированных возбудителем COVID-19. Многочисленные исследования подтверждают жизнеспособность SARS-CoV-2 на пластике до 2-3 дней, что увеличивает потенциальный риск распространения возбудителя и имеет значение для эпидемиологической оценки ситуации. В настоящее время во всех странах активно разрабатываются эффективные меры по утилизации медицинских отходов.

\section{Список литературы:}

1. Joint prevention and control mechanism of the state Council. 2020. Доступно по:www.gov.cn/ xinwen/gwylflkjz53/index.htm. [Доступ 7 апреля 2020 г.].

2. Tang W. The medical waste related to COVID-2019 is cleaned up every day-the medical waste treatment market needs to be standardised. 21st Century Business Herald; 2020. accessed 08.04.2020, Доступно по:www.21jingji.com/2020/3-12/xNMDEz ODFfMTU0MjIxNQ.html. [Доступ 7 апреля 2020 г.].

3. Schlegel I. How the plastic industry is exploiting anxiety about COVID-19. 2020. Доступно по:www.greenpeace.org/usa/how-the-plastic-industry-is-exploiting-anxiety-about-co vid-19/. [Доступ 7 Апреля 2020].

4. Van Doremalen N., Bushmaker T., Morris D.H., et al. Aerosol and surface stability of SARS-CoV-2 as compared with SARS-CoV-1. N. Engl. J. Med. 2020. https://doi.org/10.1056/NEJMc2004973.

5. Kampf G., Todt D., Pfaender S., et al. Persistence of coronaviruses on inanimate surfaces and its inactivation with biocidal agents. J Hosp Infect. 2020; 104(3):246-51.

6. La generació de residus municipals a Catalunya ha caigut un $17 \%$ durant el mes de con- finament per la COVID-19 [Электронный ресурс]. Доступен по: https:/govern.cat/ salapremsa/notes-premsa/384304/generacio-residus-municipals-catalunya-ha-caigut-17-percentdurant- mes-confinament-covid-19 (Дата обращения 19 мая 2020 г.)

7. La Agencia de Residuos de Cataluña ha establecido diferentes opciones para tratar los residuos sanitarios en el periodo COVID-19 [Электронный ресурс]. Доступен по: http://residus.gencat.cat/es/actualitat/noticies/detall/residus-sanitaris-COVID19-00001 (Дата обращения 21 июля 2020 г.)

8. Cities policy responsess [Электронный ресурс]. Доступен по: https://read. oecd- 
ilibrary.org/view/?ref=126_126769-yen45847kf\&title=Coronavirus-COVID-19-Cities-Policy-Responses (Дата обращения 21 июля 2020 г.)

9. Municipal Waste Management in European Union COVID - 19 [Электронный ресурс]. Доступен по: https://acrplus.org/en/municipal-waste-management-covid-19\#europeanunion (Дата обращения 21 июля 2020 г.)

10. Peeri N.C., Shrestha N., Rahman M.S., et al.The SARS, MERS and novel coronavirus (COVID-19) epidemics, the newest and biggest global health threats: What lessons have we learned. International Journal of Epidemiology. Epub ahead of print 22 February 2020. DOI: 10.1093/ije/dyaa033.

11. Coronavirus Disease 2019 (COVID-19). Situation summary - Updated 15 March 2020. Доступно по: https://www.cdc.gov/coronavirus/2019-ncov/summary.html (Дата обращения 21 июля 2020 г.)

12. Chan J.F., Yuan S., Kok K.H., et al. A familial cluster of pneumonia associated with the 2019 novel coronavirus indicating personto-person transmission: A study of a family cluster. The Lancet .2020;395:514-523.

13. Doremalen N., Bushmaker T., Morris D.H., et al.Aerosol and surface stability of HCoV-19 (SARS-CoV-6 2) compared to SARS-CoV-1. DOI: 10.1101/2020.03.09.20033217

14. Cruvinel V.R.N., Marques C.P., Cardoso V., et al. Health conditions and occupational risks in a novel group: Waste pickers in the largest open garbage dump in Latin America. BMC Public Health .2019;581: 16-19.

15. Elachola H., Assiri A.M., Memish Z.A. Int. J. Infect. Dis.,2014; 20: 77-78.

16. Yang A.P., Seale H., Macintyre R., et al. ORIGINAL Mask-wearing and Respiratory Infection in Healthcare Workers in Beijing, China.2008.

17. Elachola H., Ebrahim S.H., Gozzer E. COVID-19.Facemask use prevalence in international airports in Asia, Europe and the Americas, March 2020. Travel Med. Infect. Dis., 101637

18. Leung C.C., Lam T.H., Cheng K.K. Assessment of microplastics in freshwater systems: a review. Sci. Total Environ. 2020;707.

19. Barasheed O., Alfelali M., Mushta S., et al. Uptake and effectiveness of facemask against respiratory infections at mass gatherings: a systematic review. Int. J. Infect. Dis.2006; 47:105-111.

20. World Health Organization (WHO). Shortage of personal protective equipment endangering health workers worldwide. March, 3. Доступно по:https://www.who.int/newsroom/detail/03-03-2020-shortage-of-personal-protective-equipment-endangering-healthworkers. (Дата обращения 21 июля 2020 г.)

21. China focus: mask makers go all out in fight against novel coronavirus. February, 06. Доступно по: http://www.xinhuanet.com/english/2020-02/06/c_138760527.html. (Дата обращения 21 июля 2020 г.)

22. Ministry of Economy, Trade and Industry, Japan (METI), 2020. Current status of production and supply of face masks, antiseptics and toilet paper. April 23. Доступно по: https:// www.meti.go.jp/english/covid-19/mask.htm (Дата обращения 21 июля 2020 г.)

23. Worldometer, 2020. COVID-19 Coronavirus Pandemic. Мау, 07. Доступно по: https://www.worldometers.info/coronavirus/ (Дата обращения 21 июля 2020 г.) 
24. Fadare O.O., Wan B., Guo L., et al. Microplastics from consumer plastic food containers: are we consuming it ? Chemosphere.2020; 253.

25. Browne M.A., Dissanayake A., Galloway T.S., et al. Ingested microscopic plastic translocates to the circulatory system of the mussel, Mytilusedulis (L.). Environ. Sci. Technol.2008; 42:5026-5031.

26. Cole M., Webb H., Lindeque P.K., et al. Isolation of microplastics in biota-rich seawater samples and marine organisms. Sci. Rep.2014; 4: 1.

27. Galloway T.S., Cole M., Lewis C. Interactions of microplastic debris throughout the marine ecosystem. Nat. Publ. Gr.2017; 1: 1-8.

28. Rist S., Carney Almroth, B., Hartmann N.B., et al. A critical perspective on early communications concerning human health aspects of microplastics. Sci. Total Environ.2018; 626:720-726.

29. Wright S.L., Thompson R.C., Galloway T.S. The physical impacts of microplastics on marine organisms: a review. Environ. Pollut.2013;178:483-492.

30. Reid A.J., Carlson A.K., Creed I.F., et al. Emerging threats and persistent conservation challenges for freshwater biodiversity. Biol. Rev.2019; 94: 849-873.

31. Shen M., Ye S., Zeng G., et al. Can microplastics pose a threat to ocean carbon sequestration? Mar. Pollut. Bull.2019; 137:157-171. 